\title{
Effects of Targeted Anticancer Medicines on Post-Cell Removal Surface Morphology of Cancer Cells Cultivated on 3-Aminopropyltriethoxysilane Surface
}

\author{
Chung-Ping Hsu ${ }^{1,2}$, You-Lin Wü ${ }^{3 *}$, Wan-Yun Lee ${ }^{3}$, Li-Wen $\mathrm{Li}^{1}$ and Jing-Jenn Lin ${ }^{4}$ \\ ${ }^{1}$ Division of Thoracic Surgery, Department of Chest Surgery, Taichung Veteran General Hospital, Taichung, Taiwan, Republic of China \\ ${ }^{2}$ School of Medicine, National Yang Ming University, Taipei, Taiwan, Republic of China \\ ${ }^{3}$ Department of Electrical Engineering, National Chi Nan University, Puli, Nantou, Taiwan, Republic of China \\ ${ }^{4}$ Department of Applied Materials and Optoelectronic Engineering, National Chi Nan University, Puli, Nantou, Taiwan, Republic of China
}

\begin{abstract}
A post-cell-removal surface morphology (PCRSM) profiling technique was used to identify the effects of targeted anticancer medicines on cancer cells. Living non-small lung cancer cells, A549 and H1299, were cultivated on a 3-aminopropyltriethoxysilane ( $\mathrm{Y}$-APTES) coated silicon wafer surface with and without targeted anticancer medicine added in the culture medium. Atomic force microscopy (AFM) was used to examine the surface morphology profile on the $Y$-APTES wafer surface after removing the cells. Two different targeted anticancer medicines, epidermal growth factor receptor (EGFR)-inhibitor Iressa (gefitinib) and protein kinase c (PKC)-inhibitor Staurosporine were examined. Our experimental results show that only the cancer cells treated with Staurosporine can have the PCRSM profiles resemble to those of normal cells, whereas those treated with Iressa reserve the PCRSM profiles of the pre-medicine treated cancer cells. This observation indicates that the PCRSM technique is able to detect the cell-traction force difference caused by EGFR-inhibitor and PKC-inhibitor, respectively and Staurosporine is more effective than Iressa in deactivating the cell-substrate interaction of the cancer cells.
\end{abstract}

Keywords: Surface morphology; Targeted anticancer medicine; Lung cancer; Cell traction force; Atomic force microscopy; Cellsubstrate interaction

\section{Introduction}

Activating the apoptosis mechanism of the cancer cells has been recognized as one of the key factors in development of anticancer medicines. It has also been pointed out that manipulation of the intrinsic pathway for mitochondria-dependent apoptosis activation is an efficient way for cancer cells treatment [1]. Upon anticancer medicine treatment, the mitochondrial proteins cytochrome $c$ (cyt-c) and Smac protein/direct inhibitor of apoptosis (IAP) binding protein with low isoelectric point (pI) (DIABLO) are released into the cytosol. Here, they synergistically activate capiases through activating apoptotic protease activating factor 1 (APAF-1) and relieving the apoptotic inhibition with IAPs [2-7]. In recent years, new agents aimed at targetspecific intracellular pathways, such as angiogenesis inhibitors, EGFR inhibitors, and PKC inhibitors related to the distinctive properties of cancer cells have been developed and tested [8-17]. On the other hand, in vitro testing of cancer cells treated with anticancer medicines using cell-based essays has become the usual way for development of anticancer medicines. In previous work, we reported that the cellsubstrate interaction property can be determined via cultivating cells on a $\gamma$-APTES modified silicon dioxide $\left(\mathrm{SiO}_{2}\right)$ surface and then measure the PCRSM profiles with atomic force microscopy technique [18]. With this method, we were able to observe the evolvement of the cell-substrate interaction over time and found that the cancer and normal cells would leave different imprints on the $\gamma$-APTES surface due to different cell traction forces that are generated through actomyosin tractions and actin polymerization. In this work, we used the PCRSM profiles technique to investigation the cancer cells treated with or without the targeted anticancer medicines, Iressa and Staurosporine. These two anticancer medicines were developed based on the aforementioned target-specific intracellular pathways related mitochondria-dependent apoptosis mechanism, and are commonly used for non-small lung cancer (NSLC) treatment. It should be noted that Iressa is an anticancer medicine that inhibits EGFR tyrosine kinase through binding to the adenosine triphosphate (ATP)-binding site of the enzyme $[19,20]$, whereas Staurosporine is a medicine that prevents the ATP binding with the PKC to deactivate the ability of growth and transformation of the affected cells [8]. In addition to the two NSLC cells of A549 and H1299, the Madin-Darby canine kidney (MDCK) epithelial cell, one of the normal cells commonly used for biochemical analysis, was also examined for the comparison. The PCRSM profiles of those cells were obtained via cultivation of the cells on $\gamma$-APTES surface after treatment either with or without anticancer medicines and measurement of the imprints left after cells removal. The reason we cultivated the cells on $\gamma$-APTES layer is that rich $\mathrm{NH}_{2}$ bonds can be provided on its surface and give the cells better attachment $[21,22]$.

\section{Materials and Methods}

\section{Substrate preparation}

A p-type (100) silicon wafer covered with a $2 \mathrm{~nm}$-thick $\mathrm{SiO}_{2}$ surface layer was used as the supporting substrate. A $1 \%$ ethanol solution of $\gamma$-APTES was then spin-coated onto the $\mathrm{SiO}_{2}$ surface and cured at $120^{\circ} \mathrm{C}$ for $5 \mathrm{~min}$ on a hot plate. The final thickness of $\gamma$-APTES layer was determined with ellipsometry to be almost $550 \mathrm{~nm}$. After coating with $\gamma$-APTES, the Si wafer was subjected to sterilization in an autoclave sterilizer at $110^{\circ} \mathrm{C}$ for $90 \mathrm{~min}$ in vacuum. The $\mathrm{Si}$ wafer was then divided into 12 pieces and placed in a 12 -well culture plate for cell cultivation.

*Corresponding author: You-Lin Wu, Department of Electrical Engineering National Chi Nan University, 301 University Rd., Puli, Nanto, Taiwan, 54561, Tel: +886-49-2910960 (X-4805); Fax: +886-49-2917810; E-mail: ylwu@ncnu.edu.tw

Received April 26, 2014; Accepted May 28, 2014; Published May 30, 2014

Citation: Hsu CP, Wu YL, Lee WY, Li LW, Lin JJ (2014) Effects of Targeted Anticancer Medicines on Post-Cell Removal Surface Morphology of Cancer Cells Cultivated on 3-Aminopropyltriethoxysilane Surface. Med chem S1: 007. doi:10.4172/2161-0444.S1-007

Copyright: $\odot 2014$ Hsu CP, et al. This is an open-access article distributed under the terms of the Creative Commons Attribution License, which permits unrestricted use, distribution, and reproduction in any medium, provided the original author and source are credited. 


\section{Cell culture and removal}

Before cultivation of cells on the substrate surface, all the cell lines were immersed in a $5 \mathrm{~mL}$ Dulbecco modified Eagle's medium (DMEM) supplemented with $10 \%$ fetal bovine serum containing $10 \mathrm{mg} / \mathrm{mL}$ penicillin/ streptomycin and $2 \mathrm{~mL}$ glutamine, and cultured in an incubator with $5 \% \mathrm{CO}_{2}$ at $37^{\circ} \mathrm{C}$. After cultivation of $\mathrm{A} 549$ and $\mathrm{H} 1299$ (obtained from the American Type Culture Collection, Manassas, VA, USA) for 3 days and the MDCK cells for 7 days, each cell line was seeded separately onto the $\gamma$-APTES modified silicon surface placed in the 12-well culture plate with an initial concentration of $8 \times 10^{3}$ cell/ well. The 12-well plate was then immersed in culture medium DMEM solutions either with or without anticancer medicine addition. For the anticancer medicine examinations, $10 \mu \mathrm{L}$ Iressa and Staurosporine (Sigma-Aldrich, USA) solutions with various concentrations were prepared and added separately to the culture medium. The cells cultured on the $\gamma$-APTES modified $\mathrm{SiO}_{2}$ surface were then removed after $24 \mathrm{~h}$ of cultivation, respectively through immersing the samples in an $75 \%$ ethanol solution for $10 \mathrm{~min}$ followed by a phosphate buffer solution (PBS) wash-off process and afterward drying at room temperature under normal atmospheric environment. The $24 \mathrm{~h}$ cultivation is needed to ensure that the cells are completely adhered to the substrate surface. Imprints were left on the $\gamma$-APTES surface after the removal of cells. Optical microscope was used to make sure the removal of the cells.

\section{PCRSM profiles measurement}

For surface morphology image of the cells before they were removed, we placed each cell line cultured on the $\gamma$-APTES modified $\mathrm{SiO}_{2}$ surface into a dish-type slot filled with culture medium and loaded it in to a SEIKO 300HV AFM system for surface morphology measurement which was then carried out under a liquid environment. After the removal of the cells, each sample was again loaded into a SEIKO 300HV AFM system for surface morphology image measurement that was performed under a vacuum of $5 \times 10^{-6}$ Torr. The surface morphology examinations were carried out under tapping mode with a resonant frequency of $130 \mathrm{kHz}$, a force constant of $15 \mathrm{~N} / \mathrm{m}$ and a speed of $0.7 \mathrm{~Hz}$. The PCRSM profiles were obtained by scanning a straight line across the imprint of each cell using the AFM tip. In this work, a Si tip with a radius of smaller than $7 \mathrm{~nm}$ was used for all the measurements. Figure 1 shows schematically the process steps of the PCRSM profiling technique.

\section{Results}

As we reported in our previous paper, the PCRSM profiling technique enables us not only to observe the evolvement of the cellsubstrate interaction over time, but also differentiate the difference of cell-substrate interaction between normal and cancer cells [18]. Prior to measuring the PCRSM profiles, we checked the surface morphology images before and after the removal of the cells. Figure 2(a) shows the AFM surface morphology images of the normal cells MDCK, Beas-2B, and MRC5 cultivated for $24 \mathrm{~h}$ on a $\gamma$-APTES modified $\mathrm{SiO}_{2}$ surface before they were removed. Their corresponding PCRSM AFM images are shown in figure $2 \mathrm{~b}$. Figures $3 \mathrm{a}$ and $3 \mathrm{~b}$ show the AFM surface morphology images of cancer cells A549 and H1299 cultivated for $24 \mathrm{~h}$ on a $\gamma$-APTES surface before and after they were removed, respectively. Both normal and cancer cells were observed being completely adhered to the substrate surface and imprints were left on the $\gamma$-APTES surface after the cells were removed due to cell-substrate interaction. Figure 4a shows the PCRSM profiles of the normal cells Beas-2B, MRC5, and MDCK, whereas figure $4 \mathrm{~b}$ depicts those of the cancer cells A549 and H1299 after $24 \mathrm{~h}$ cultivation on $\gamma$-APTES surface, as reported by Hsu et al. [18]. The surface morphology profiles shown in figure 4 were normalized to the original $\gamma$-APTES surface before they were removed, that is, the original $\gamma$-APTES surface was taken as reference zero. As observed, the cancer cells tend to form deeper trench along the circumference and a protrusion at the center of the PCRSM profiles, whereas the normal cells exhibit flatter PCRSM profiles at the bottom of the adhesion region. That is, the PCRSM profile for the cancer cells is nearly in W-shape, but that of the normal cells is somewhat like a flat line. In this work, only the MDCK cell was used to be compared with the cancer cells since it produces the deepest PCRSM profiles, and among the three normal cells is closest to the PCRSM profiles of the cancer cells. In order to check the effect of anti-cancer medicine on the PCRSM profiles, we added anti-cancer medicines Staurosporine and Iressa into the culture medium, respectively. Figure $5 \mathrm{a}$ and bshows respectively the normalized PCRSM profiles of cancer cells A549 and H1299 after $24 \mathrm{~h}$ cultivation in culture medium with various

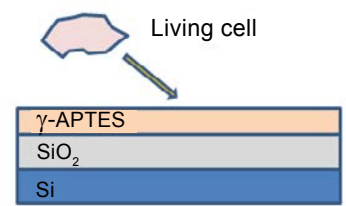

(a) Cell Seeding

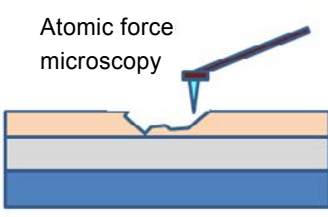

(d) Surface Morphology Profile Measurement
In culture medium with or without anti-cancer medicine

(b) Cell Cultivation

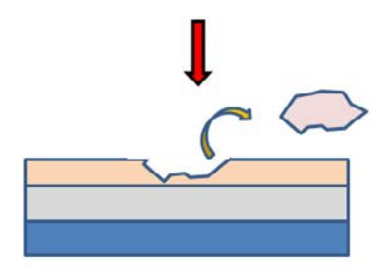

(c) Cell Removal

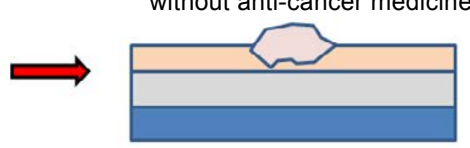

Figure 1: Schematic diagram of the process steps of the PCRSM profiling technique.

(a)
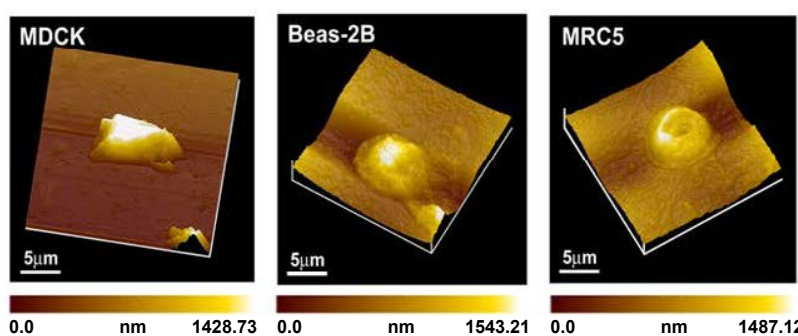

0.0

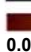

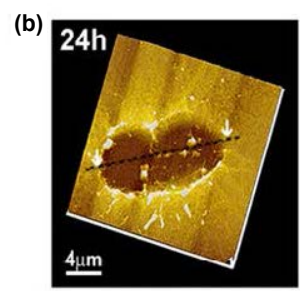

0.0

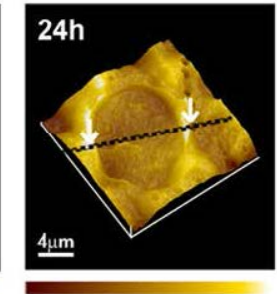

nm $\quad 184.75$

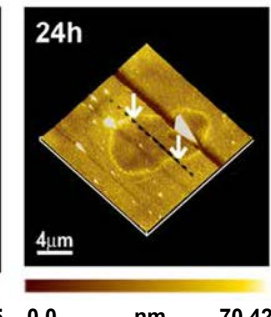

$\mathrm{nm} \quad \mathbf{7 0 . 4 2}$
Figure 2: (a) AFM surface morphology images of normal cells MDCK, Beas$2 \mathrm{~B}$ and MRC5, and (b) their corresponding PCRSM AFM images. The dashed lines shown here are the lines along which the AFM probe scanned for the PCRSM profile measurement. ${ }^{10}$ 
(a)

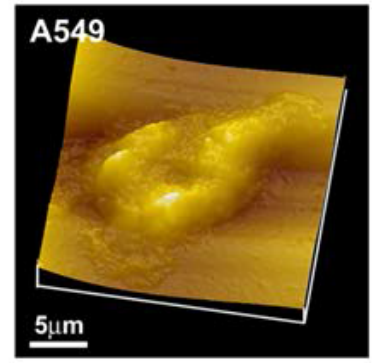

0.0

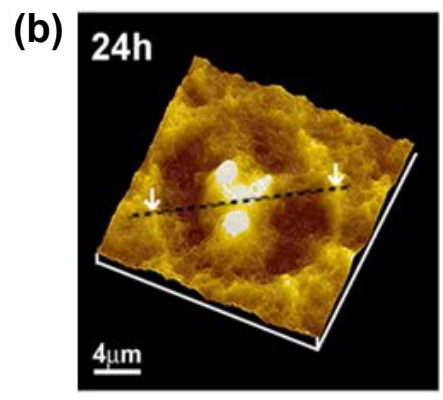

0.0
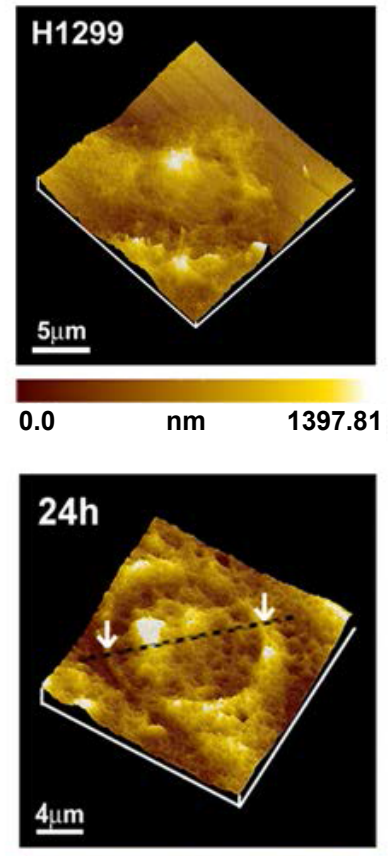

0.0

$\mathrm{nm}$

452.01

Figure 3: (a) AFM surface morphology images of cancer cells A549 and $\mathrm{H} 1299$, and (b) their corresponding PCRSM AFM images. The dashed lines shown here are the lines along which the AFM probe scanned for the PCRSM profile measurement.

concentration of anticancer medicine Staurosporine. As observed, for both the A549 and H1299, the PCRSM profiles change from W-shape to nearly flat line as the Staurosporine concentration increases. The same amount of Staurosporine (100 nM) was also added to the culture medium for the normal cell MDCK. The PCRSM profiles of the MDCK cells after treatment with and without anticancer medicines are shown in figure 6a. The PCRSM profiles of the cancer cells A549 and H1299 treated with and without $100 \mathrm{nM}$ Staurosporine are given in figure $6 \mathrm{~b}$ and $6 c$, respectively, for comparison. The difference of the PCRSM profiles between normal cells and cancer cells is clear. As observed, although the depth of PCRSM profile of the MDCK cell decreases after the treatment of anticancer medicine, the profile basically remains the flat line shape. For cancer cells, the PCRSM profiles also turn into nearly flat after been treated with $100 \mathrm{nM}$ Staurosporine.

We also conducted an experiment through culturing the cancer cells in Staurosporine-containing medium with concentrations of 10 and $100 \mathrm{nM}$ for $24 \mathrm{~h}$ followed by replacing the culture medium with anticancer medicine free ones. Then, their PCRSM profiles were taken after another $24 \mathrm{~h}$ cultivation period. The resultant PCRSM profiles for the cancer cells A549 and H1299 are shown in figure 7a and b, respectively. The PCRSM profiles of the cancer cells H1299 and A549 before and after the treatment with $100 \mathrm{nM}$ Staurosporine are also included in figure 7 for comparison. As shown in figure $7 \mathrm{a}$, after replacing with anticancer medicine free culture medium the PCRSM profile of A549 changes from almost flat profile to the one with deeper trench along the circumference and a protrusion at the center, regardless of whether the cancer cells had been treated with 10 or 100 nM Staurosporine. That is, the PCRSM profiles change from nearly flat-line shape to W-shape. Similar result was observed for the PCRSM profiles of the cancer cell H1299, as shown in figure 7b. Anti-cancer

medicine Iressa, at different concentrations, was added to the culture mediums to check its effect on the PCRSM profiles of the cancer cells. We found that the PCRSM profiles for both A549 and H1299 remained in a W-shape, even when the Iressa concentration was increased to $50 \mu \mathrm{M}$. To compare the difference between the targeted anticancer medicines Staurosporine and Iressa, the respective PCRSM profiles of the cancer cells A549 and H1299 after treatment with $100 \mathrm{nM}$ Staurosporine and $50 \mu \mathrm{M}$ Iressa as well as subjected to no anticancer treatment are shown in figure 8a and b. For both A549 and H1299, the PCRSM profiles tend to become flat once after being subjected to 100 $\mathrm{nM}$ Staurosporine, whereas the other ones remain in $\mathrm{W}$-shape after treatment with $50 \mu \mathrm{M}$ Iressa, but the central protrusion increases.

\section{Discussion}

The cell-substrate interaction has been recognized as an indication that cells will generate a local force via so-called cell-extracellular matrix (ECM) interactions. It has been confirmed that it is the traction force caused by actin polymerization at the cell's leading membrane edge that transmits the contractility force to the ECM via the primary mediators' focal adhesion protein integrins [23-25]. In addition, reports have shown that cell's central region also plays an important role in cell-substrate interaction $[26,27]$. Since cell-substrate interaction is
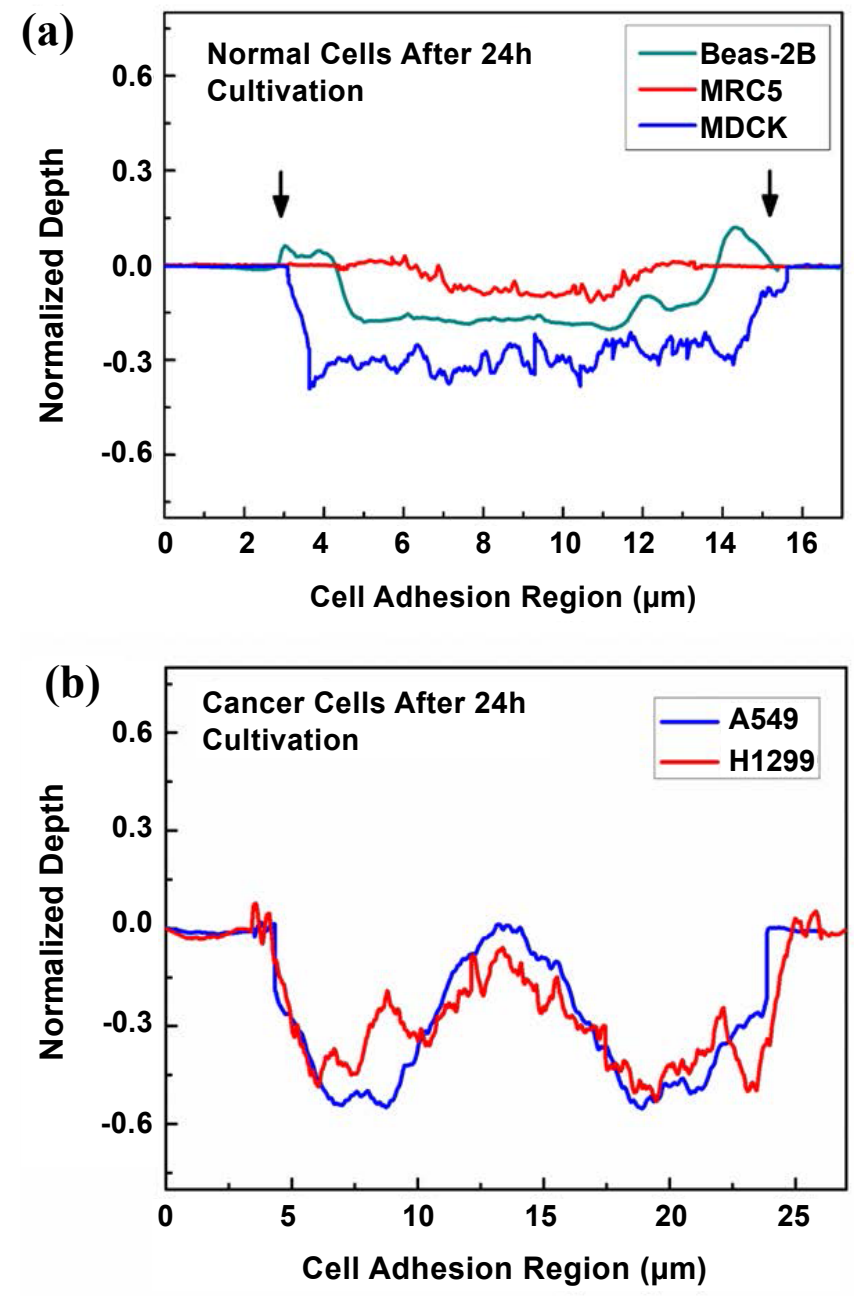

Figure 4: Normalized PCRSM profiles for the (a) Normal cells MDCK, Beas2B, and MRC5, and (b) Cancer cells A549 and H1299. ${ }^{10}$ 

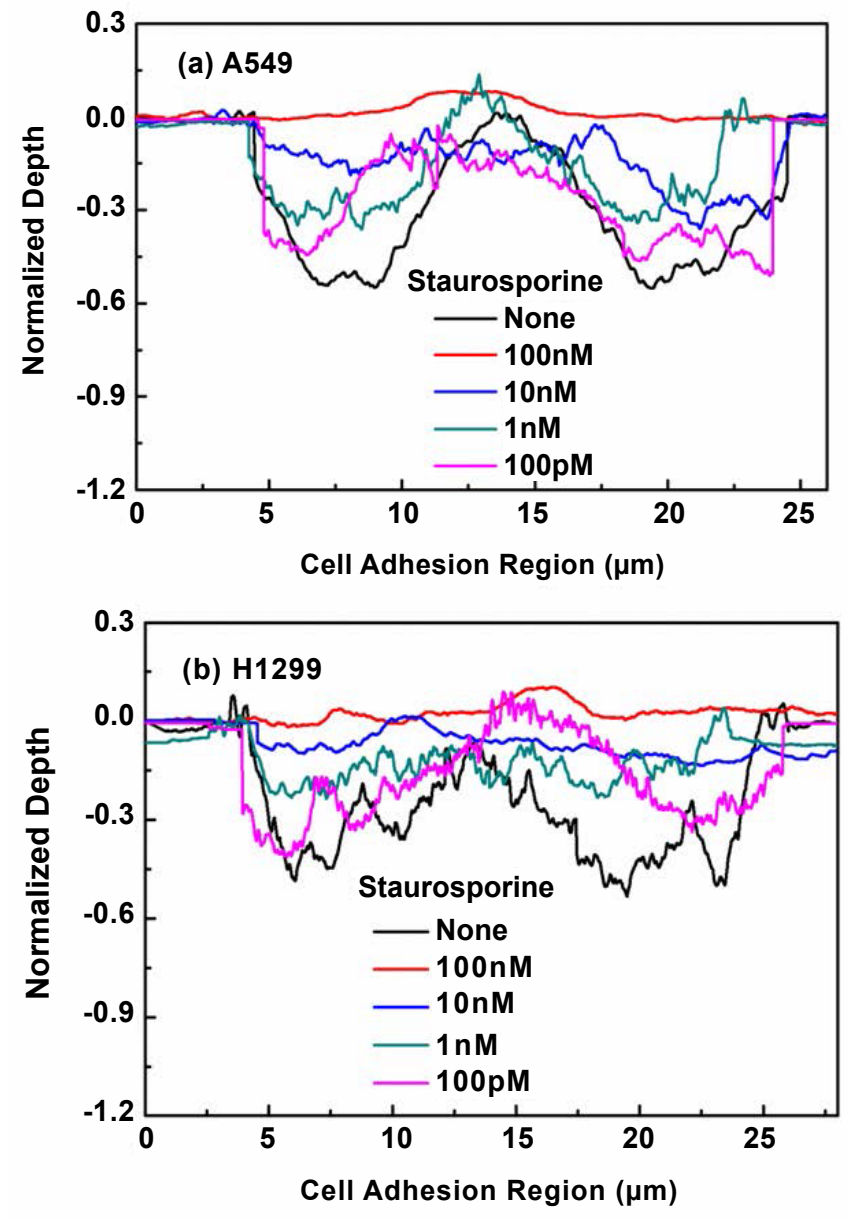

Figure 5: Normalized PCRSM profiles for the cancer cells (a) A549, (b) $\mathrm{H} 1299$ subjected to targeted anti-cancer medicine Staurosporine with various concentrations.

directly related to the traction force of the cell, the cell property can be judged from the imprint it leaves on the soft substrate surface onto which the cell is cultured. The cancer cells and the normal cells show different surface morphology profiles of the imprints, i.e., they have the PCRSM profiles due to different cell-substrate interactions. It is found that the PCRSM profile for the cancer cells is nearly in W-shape, but that of the normal cells is somewhat like a flat line, as shown in figure 4. Based on the PCRSM profiling technique, we compared the effects of anticancer medicines, Staurosporine and Iressa, on the cell-substrate interaction of NSCLC cancer cells A549 and H1299. Figure 5 shows that the PCRSM profiles of the cancer cells changed from a W-shape into a nearly flat-line when the Staurosporine concentration was increased. At a Staurosporine concentration of $100 \mathrm{nM}$, the PCRSM profile of the cancer cells had a flat-line profile. In other words, the PCRSM profiles of the cancer cells tended to become similar to those of the normal cells after being treated with a certain amount of Staurosporine. It has been reported that nuclear apoptosis of the NSCLC cell can be induced with the use of Staurosporine [28]. It is therefore assumed that the flat lines of the PCRSM profiles, after having been treated with Staurosporine, are caused by the activation of cell apoptosis thereby weakening the cell traction force. The PCRSM profiles of the normal cell MDCK remained a flat-line after being treated with the same amount (100 $\mathrm{nM}$ ) of Staurosporine, but the depth of the imprint was shallower (Figure 6). This result indicates that the Staurosporine does affect the cell-substrate interaction of the normal cells; however, it has further profound effect on the cell traction force of the cancer cells. Apparently, prevention of ATP binding with PKC can effectively reduce the cellsubstrate interaction of the cancer cells due to the activation of cell apoptosis or nuclear condensation. It is worth noting that the effect of Staurosporine on the PCRSM profiles is reversible. In other words, the PCRSM profiles changed from a nearly flat-line shape to a $\mathrm{W}$-shape when the Staurosporine-containing culture mediums were replaced with anticancer medicine free ones, (Figure 7). It is also noticed that, the recovered PCRSM profiles of the cancer cell H1299 are closer to the PCRSM profiles of the cancer cells subjected to no medicine treatment than that of the cancer cell A549. This is an indication that the malignancy of A549 is much more severe than that of H1299 [2931]. Surprisingly, the effect of Iressa on the PCRSM profiles of cancer cells is not the same as that of Staurosporine. The PCRSM profiles maintained a W-shape for both the cancer cells A549 and H1299 after being subjected to a much higher concentration $(50 \mu \mathrm{M})$ of Iressa. In figure 8 we compared the PCRSM profiles of the cancer cells subjected to $100 \mathrm{nM}$ Staurosporine and $50 \mu \mathrm{M}$ Iressa, respectively. As observed,
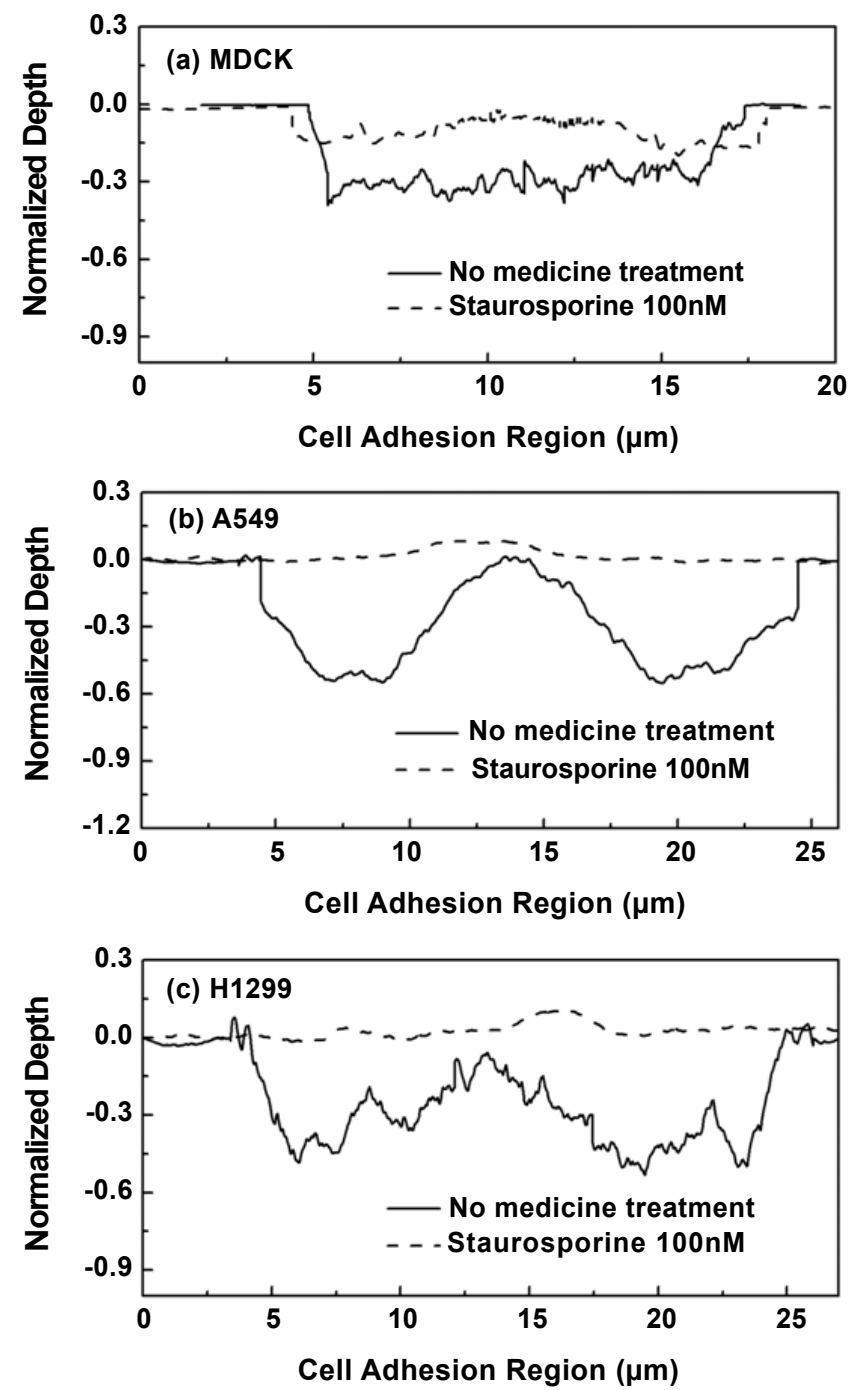

Figure 6: Comparison of the normalized PCRSM profiles for (a) Normal cell MDCK, (b) Cancer cell A549, (c) Cancer cell H1299 subjected to no anticancer medicine and $100 \mathrm{nM}$ Staurosporine. 

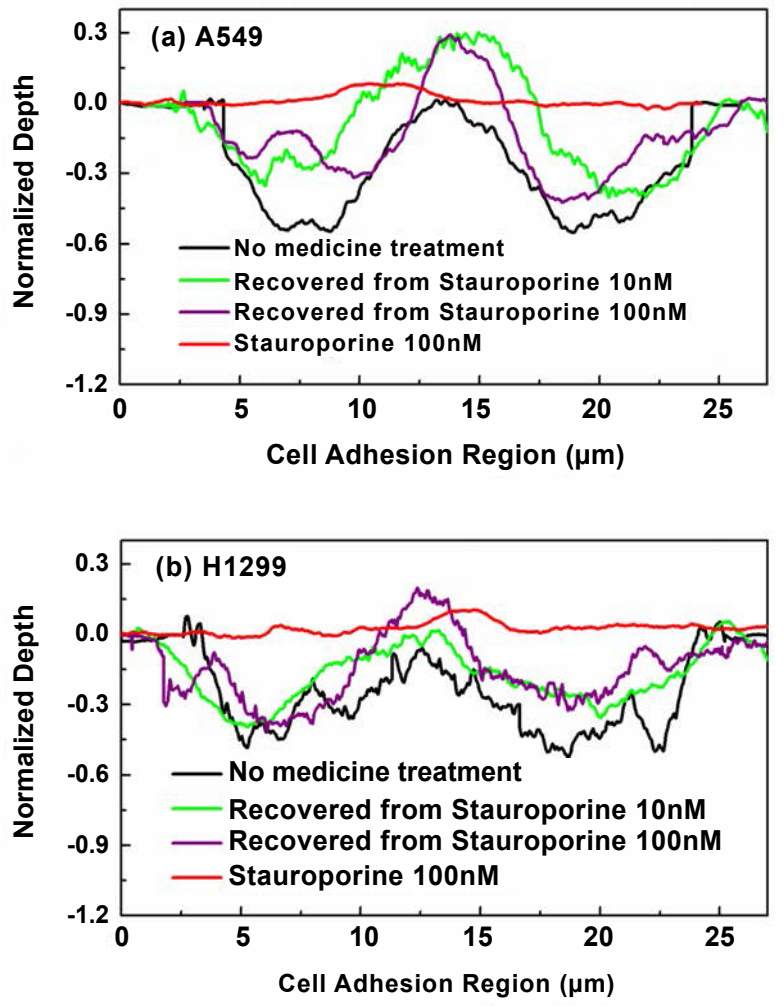

Figure 7: Normalized PCRSM profiles for the cancer cells (a) A549, (b) H1299 obtained through culturing the cells in Staurosporine-containing medium with concentration of 10 and $100 \mathrm{nM}$, respectively, for $24 \mathrm{~h}$ followed by replacing the culture medium with anticancer medicine free ones for another $24 \mathrm{~h}$ period.
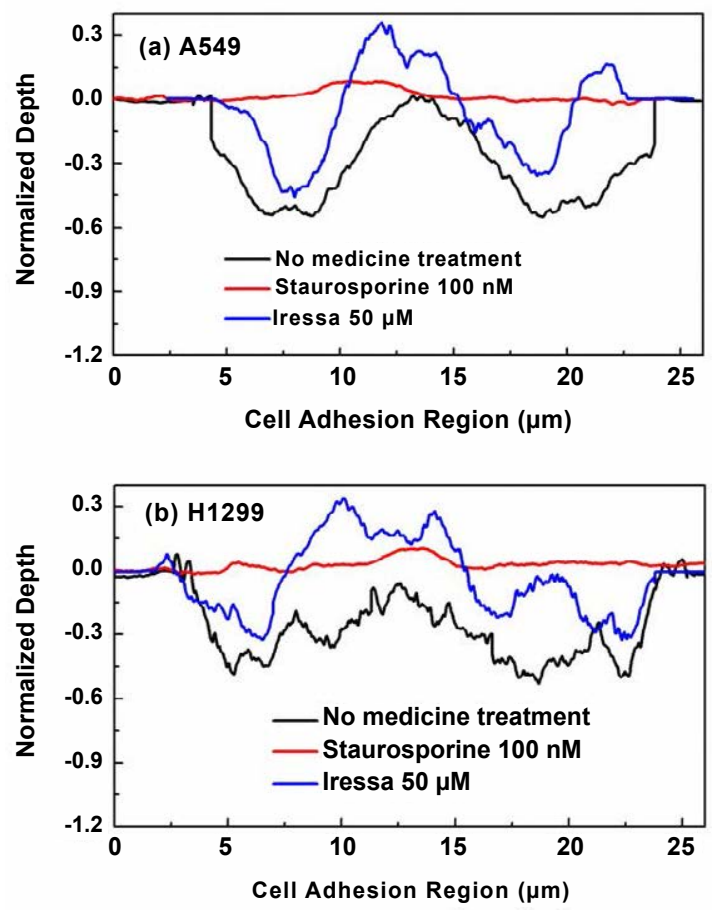

Figure 8: Comparison of the normalized PCRSM profiles for the cancer cells (a) A549, (b) H1299 subjected to no anticancer medicine, $100 \mathrm{nM}$ Staurosporine, and $50 \mu \mathrm{M}$ Iressa. the effects of Staurosporine and Iressa on the cell-substrate interactions of the cancer cells were different. The PCRSM profiles adopted a flatline shape after a $100 \mathrm{nM}$ Staurosporine treatment, while those that were treated with $50 \mu \mathrm{M}$ Iressa maintained their $\mathrm{W}$-shape. From a cell-substrate interaction point of view it seems to be apparent that the PKC-inhibitor Staurosporine is more effective than the EGFR inhibitor Iressa, which is in agreement with the reports from $\mathrm{Wu}$ et al. [31] and Notbohm et al. [32]. It was also noticed that, although the PCRSM profiles remained in a $\mathrm{W}$-shape, the central protrusion of the PCRSM profiles increased after treatment with Iressa. This observation implies that Iressa induces an increase in cell traction force toward the center region of the cell, along the circumference of the cell.

\section{Conclusion}

Based on our previously developed PCRSM profiling technique, we compared the effects of anticancer medicines, Staurosporine and Iressa, on the cell-substrate interaction of NSCLC cancer cells A549 and H1299. It was observed that the PCRSM profiles of the cancer cells change from $\mathrm{W}$-shape into flat-line shape after treatment with a certain amount (100 nM) of Staurosporine, whereas the other ones remain in $\mathrm{W}$-shape after treatment with the same amount of Iressa. This indicates that the PKC-inhibitor Staurosporine is more effective than the EGFR inhibitor Iressa on reducing the cell traction force. No report in the literature has addressed the differences between the EGFR-inhibitor and $\mathrm{PKC}$-inhibitor on the cell-substrate interaction, although it has been reported that both Staurosporine and Iressa induce the shape and morphology change of NSCLC cells $[10,32,33]$. It is evident that the PCRSM profiling technique allows us to see the difference of the cellsubstrate interaction between the EGFR-inhibitor and PKC-inhibitor anti-cancer medicines, although further investigations are needed to disclose the actual mechanism behind these observations. We believe that the PCRSM profiling technique could be used as a tool for the development of new targeted anticancer medicines in vitro.

\section{Acknowledgment}

This work was financially supported by the Taichung Veterans General Hospital-National Chi Nan University Joint Research Program under contract no. TCVGH-NCNU977903.

\section{References}

1. Shi Y (2001) A structural view of mitochondria-mediated apoptosis. Nat Struct Biol 8: 394-401.

2. Chang GC, Yu CTR, Tsai CH, Tsai JR, Chen JC, et al. (2008) An epidermal growth factor inhibitor, Gefitinib, induces apoptosis through a p53-dependent upregulation of pro-apoptotic molecules and downregulation of anti-apoptotic molecules in human lung adenocarcinoma A549 cells. Eur J Pharmacol 600: 37-44.

3. Chi SL, Pizzo SV (2006) Angiostatin is directly cytotoxic to tumor cells at low extracellular $\mathrm{pH}$ : a mechanism dependent on cell surface-associated ATP synthase. Cancer Res 66: 875-882.

4. Cragg MS, Kuroda J, Puthalakath H, Huang DC, Strasser A (2007) Gefitinibinduced killing of NSCLC cell lines expressing mutant EGFR requires BIM and can be enhanced by BH3 mimetics. PLoS Med 4: 1681-1689.

5. Gong Y, Somwar R, Politi K, Balak M, Chmielecki J, et al. (2007) Induction of BIM is essential for apoptosis triggered by EGFR kinase inhibitors in mutant EGFR-dependent lung adenocarcinomas. PLoS Med 4: e294.

6. Lagadic-Gossmann D, Huc L, Lecureur V (2004) Alterations of intracellular pH homeostasis in apoptosis: origins and roles. Cell Death Differ 11: 953-961.

7. Tafani M, Cohn JA, Karpinich NO, Rothman RJ, Russo MA, et al. (2002) Regulation of intracellular $\mathrm{pH}$ mediates Bax activation in HeLa cells treated with staurosporine or tumor necrosis factor-alpha. J Biol Chem 277: 49569-49576.

8. Joseph B, Marchetti P, Formstecher P, Kroemer G, Lewensohn R, et al. (2002) Mitochondrial dysfunction is an essential step for killing of non-small cell lung carcinomas resistant to conventional treatment. Oncogene 21: 65-77. 
Citation: Hsu CP, Wu YL, Lee WY, Li LW, Lin JJ (2014) Effects of Targeted Anticancer Medicines on Post-Cell Removal Surface Morphology of Cancer Cells Cultivated on 3-Aminopropyltriethoxysilane Surface. Med chem S1: 007. doi:10.4172/2161-0444.S1-007

9. Fabian MA, Biggs WH, Treiber DK, EAtteridge C, Azimioara MD, et al. (2005) A small molecule-kinase interaction map for clinical kinase inhibitors. Nat Biotechnol 23: 329-336.

10. Gallego MA, Joseph B, Hemstrom TH, Tamiji S, Mortier L, et al. (2004) Apoptosis-inducing factor determines the chemoresistance of non-small-cell lung carcinomas. Oncogene 23: 6282-6291.

11. Maemondo M, Inoue A, Kobayashi K, Sugawara S, Oizumi S, et al. (2010) Gefitinib or chemotherapy for non-small-cell lung cancer with mutated EGFR. N Engl J Med 362: 2380-2388.

12. Rosell R, Felip E, Garcia-Campelo R, Balana C (2004) The biology of nonsmall-cell lung cancer: identifying new targets for rational therapy. Lung Cancer 46: $135-148$

13. Yeow WS, Ziauddin MF, Maxhimer JB, Shamimi-Noori S, Baras A, et al. (2006) Potentiation of the anticancer effect of valproic acid, an antiepileptic agent with histone deacetylase inhibitory activity, by the kinase inhibitor Staurosporine or its clinically relevant analogue UCN-01. Br J Cancer 94: 1436-1445.

14. Prahallad A, Sun C, Huang S, Di Nicolantonio F, Salazar R, et al. (2012) Unresponsiveness of colon cancer to $\operatorname{BRAF}(\mathrm{V} 600 \mathrm{E})$ inhibition through feedback activation of EGFR. Nature 483: 100-103.

15. Lee HJ, Schaefer G, Heffron TP, Shao L, Ye X, et al. (2013) Noncovalent wildtype-sparing inhibitors of EGFR T790M. Cancer Discov 3: 168-181.

16. Yamada T, Takeuchi S, Fujita N, Nakamura A, Wang W, et al. (2013) Akt kinase-interacting protein, a novel therapeutic target for lung cancer with EGFR-activating and gatekeeper mutations. Oncogene 32: 4427-4435.

17. Walter AO, Sjin RT, Haringsma HJ, Ohashi K, Sun J, et al. (2013). Discovery of a Mutant-Selective Covalent Inhibitor of EGFR that Overcomes T790MMediated Resistance in NSCLC. Cancer Discov 3: 1404-1415.

18. Hsu CP, Hsu PY, Wu YL, Hsu WY, Lin JJ (2012) Evolvement of cell-substrate interaction over time for cells cultivated on a 3-aminopropyltriethoxysilane (?-APTES) modified silicon dioxide (SiO2) surface. Appl Surf Sci 258: 8641 8648.

19. Kris MG, Natale RB, Herbst RS, Lynch TJ Jr, Prager D, et al. (2003) Efficacy of Gefitinib, an inhibitor of the Epidermal Growth Factor Receptor Tyrosine Kinase, in Symptomatic Patients with No-Small-Cell Lung Cancer. J Am Med Assoc 290: 2149-2158.

20. Wakeling AE, Guy SP, Woodburn JR, Ashton SE, Curry BJ, et al. (2002) ZD1839 (Iressa): an orally active inhibitor of epidermal growth factor signaling with potential for cancer therapy. Cancer Res 62: 5749-5754.
21. Davis DH, Giannoulis CS, Johnson RW, Desai TA (2002) Immobilization of RGD to $<111>$ silicon surfaces for enhanced cell adhesion and proliferation. Biomaterials 23: 4019-4027.

22. Lee MH, Brass DA, Morris R, Composto RJ, Ducheyne $P$ (2005) The effect of non-specific interactions on cellular adhesion using model surfaces. Biomaterials 26: 1721-1730.

23. Choquet D, Felsenfeld DP, Sheetz MP (1997) Extracellular matrix rigidity causes strengthening of integrin-cytoskeleton linkages. Cell 88: 39-48.

24. Geiger B, Bershadsky A, Pankov R, Yamada KM (2001) Transmembrane crosstalk between the extracellular matrix--cytoskeleton crosstalk. Nat Rev Mol Cell Biol 2: 793-805.

25. Maskarinec SA, Franck C, Tirrell DA, Ravichandran G (2009) Quantifying cellular traction forces in three dimensions. Proc Natl Acad Sci U S A 106: 22108-22113.

26. Kozlov MM, Bershadsky AD (2004) Processive capping by formin suggests a force-driven mechanism of actin polymerization. J Cell Biol 167: 1011-1017.

27. Zamir E, Katz M, Posen Y, Erez N, Yamada KM, et al. (2000) Dynamics and segregation of cell-matrix adhesions in cultured fibroblasts. Nat Cell Biol 2: 191 196.

28. Rho JK, Choi YJ, Lee JK, Ryoo BY, Na II, et al. (2009) Epithelial to mesenchymal transition derived from repeated exposure to gefitinib determines the sensitivity to EGFR inhibitors in A549, a non-small cell lung cancer cell line. Lung Cancer 63: 219-226.

29. Huang CY, Fong YC, Lee CY, Chen MY, Tsai HC, et al. (2009) CCL5 increases lung cancer migration via $\mathrm{PI} 3 \mathrm{~K}$, Akt and NF-kappaB pathways. Biochem Pharmacol 77: 794-803.

30. Su JL, Yang PC, Shih JY, Yang CY, Wei LH, et al. (2006) The VEGF-C/FIt-4 axis promotes invasion and metastasis of cancer cells. Cancer Cell 9: 209-223.

31. Wu YL, Hsu PY, Hsu CP, Lin JJ (2012) Detecting the effect of targeted anticancer medicines on single cancer cells using a poly-silicon wire ion sensor integrated with a confined sensitive window. Biomed Microdevices 14: 839-848.

32. Notbohm J, Kim JH, Asthagiri AR, Ravichandran G (2012) Three-dimensional analysis of the effect of epidermal growth factor on cell-cell adhesion in epithelial cell clusters. Biophys J 102: 1323-1330.

33. Gallego MA, Joseph B, Hemström TH, Tamiji S, Mortier L, et al. (2004) Apoptosis-inducing factor determines the chemoresistance of non-small-cell lung carcinoma. Oncogene 9: 174-185. 